\title{
LA AUTOGESTIÓN Y LA MEDIACIÓN COMO EXPERIENCIAS PARA EL PORVENIR EDUCATIVO
}

\author{
SELF-LEARNING AND MEDIATION AS EXPERIENCES FOR EDUCATIONAL \\ FUTURE
}

\author{
María Concepción Barrón Tirado \\ Universidad Nacional Autónoma de México, México \\ baticon3@hotmail.com
}

\section{Dalia Beatriz García Torres}

Universidad Nacional Autónoma de México, México

daliagarcia0511@gmail.com

(iD)

\section{Rosalina Arteaga Barrón}

Instituto Tecnológico Autónomo de México, México arte.barron01@gmail.com

Recibido: 28 de julio de 2021 Aprobado: 22 de diciembre de 2021 Publicado: 31 de diciembre de 2021

Cita sugerida: Barrón Tirado, M.C.; García Torres, D.B. y Arteaga Barrón, R. (2022). La autogestión y la mediación como experiencias para el porvenir educativo. Revista de la Escuela de Ciencias de la Educación. 1(17), 205 - 222.

\section{RESUMEN}

El presente artículo tiene como objetivo compartir los resultados de una investigación en la que nos propusimos dar seguimiento y recuperar la riqueza de las experiencias generadas por docentes que participaron en el Diplomado Docencia y mediación tecnológica de los aprendizajes, ofertado entre septiembre de 2019 y mayo de 2020. Para fines de este artículo se presenta el análisis, desde una aproximación cualitativa, de dos categorías: la autogestión y la mediación pedagógica, ambas se presentan como posibilidad para pensar en rutas 
alternativas que nos permitan tomar conciencia de nosotros mismos y afrontar futuros inéditos, donde los procesos y prácticas docentes serán fundamentales en la promoción de cambios educativos significativos a partir de un conocimiento crítico y libre.

Palabras clave: TIC - Autogestión - Mediación tecnológica - Mediación didáctica - Práctica docente.

\section{ABSTRACT}

This article aims to share the results of a research in which we set out to follow up, and recover, the richness of experience of the teachers who participated in the "Teaching and Technological Mediation of Learning" Diploma Course, offered between September 2019 and May 2020. In this article, we present an analysis from a qualitative approach - of two categories: self-learning and mediation. Both of them are introduced as possibilties to think about alternative paths that allow us to become self-aware and face unprecedented futures, where teaching processess and practices will both become fundamental in order to promote longlasting educational changes, on the basis of free and critical knowledge.

Keywords: ICT - Self-learning - Technological mediation - Didactic mediation

- Teaching practice.

\section{INTRODUCCIÓN}

Mucho se ha debatido en torno a la pandemia como oportunidad de análisis y, sobre todo, de transformación. Ha sido un evento contingente, coyuntural e incluso una vicisitud, en tanto cambio abrupto de formas de vida, que nos demostró la magnitud y prevalencia de las grandes brechas sociales, económicas y educativas, no porque no supiéramos de su existencia, sino porque ahora fue ineludible vivirlas de manera fehaciente. A pesar de ello, y en un contexto de incertidumbre, los sistemas escolares nos han pedido certezas, productividad y aprendizajes y es ahí en donde los docentes se han enfrentado a lo imprevisto, a la ambigüedad y a una significación subjetiva de lo acontecido. Si bien, por un lado, al docente se le han exigido certezas, por otro lado, dichas exigencias han sido resignificadas en el marco de su formación y de sus experiencias; cada docente le da un sentido a su vida y a su práctica, de lo contrario, caería en un vacío de no saber hacia dónde orientar su labor formativa. En este sentido, gracias a la experiencia de cada docente y a su visión de la vida, entre otros factores, es que se ha podido subsanar la educación durante la contingencia.

Ante el panorama que vivimos, el trabajo ha sido arduo y continuo; hay enojo y resistencia de diversos actores y hay ansiedad y temores por parte de los estudiantes. Además, nos enfrentamos a demandas específicas de formación para ingresar a la cultura digital y a ampliar la mirada en torno a lo que significa transitar de la presencialidad a ambientes mediados por tecnologías, pues hasta ahora ha sido claro que "[e]s una falacia o mitificación creer que una abundante 
tecnología producirá de forma casi automática una mejora en la calidad de los procesos educativos" (Area, 2016, s/p).

Si consideramos que una experiencia es tal "[...] en la medida en que no te deja indiferente: te implica, te afecta, te marca, te deja huella [...] no es algo que sucede, sino algo que se tiene" (Contreras y Pérez de Lara, 2013, p.24), lo ideal sería aprovechar esta experiencia contingente como oportunidad para promover cambios significativos. Las experiencias vividas durante la pandemia permiten plantearnos una serie de preguntas: ¿Qué significa volver a lo presencial más allá de la seguridad sanitaria? ¿Regresar a lo presencial implica regresar a lo previo? ¿Qué nos dicen las experiencias vividas? ¿A dónde nos conducen? ¿Qué razón tienen? ¿Por qué actuamos de determinada manera y no de otra?

Es necesario repensar y reflexionar sobre el sentido pedagógico de nuestra práctica, misma que se opera a partir de conocimientos teóricos previos que nos invitan a ser docentes reflexivos y analíticos. La realidad inédita nos ha exigido estas cualidades, lo cual no significa operar conocimientos acumulados, sino que, como docentes, es preciso elaborar, reelaborar y resignificar a partir de una experiencia que nos exige apertura hacia lo nuevo e inesperado. Por lo tanto, es preciso recrear y resignificar el sentido de todo lo educativo.

Lo anterior también implica ampliar nuestra visión con relación a las tecnologías digitales, pensarlas como artefactos culturales (Vygotski, 2001) históricamente determinados y que más bien "[I]lo que se aprende y lo que se enseña son decisiones humanas que no dependen de la tecnología empleada, sino de las concepciones y competencias pedagógicas del profesorado" (Area, 2016, s/p). Hace cien años, ante una pandemia (gripe española), los profesores trabajaban al aire libre con silabarios u otros artefactos; en nuestra época, son las tecnologías digitales las que nos están ayudando a salir adelante, y si bien se reconoce que por sí mismas no educan ni establecen un vínculo pedagógico, sí constituyen una mediación para establecer relaciones entre docentes, estudiantes y saberes. ¿Hacia qué caminos continuará la labor docente?, ¿qué rutas seguirá el porvenir docente? Pensar en el porvenir nos invita a reconocer que la pandemia y el periodo posterior representan:

la posibilidad que encuentra la educación latinoamericana para armarse nuevamente. La relación docente-estudiante, la organización del tiempo y espacio, la formación de grupos para mejores aprendizajes, los procesos de evaluación, la relación entre los saberes y el contenido son problemas que comprometen a [...] pensar el porvenir de la educación escolar (Morelli, 2021, p. 13).

Considerando el contexto descrito y la auténtica necesidad de construir un porvenir, el presente artículo tiene como objetivo compartir los resultados, centrados en las categorías de autogestión y mediación pedagógica, de una experiencia de investigación y docencia que ofrece la posibilidad de pensar en rutas pedagógicas alternativas no solo para prepararnos ante futuros inéditos, sino para tomar conciencia de nosotros mismos y decidir sobre nuestros procesos y prácticas docentes. 


\section{DESARROLLO}

\section{Docencia y mediación tecnológica de los aprendizajes como experiencia}

El proyecto de investigación Docencia y mediación tecnológica de los aprendizajes recupera la experiencia producida en el Diplomado del mismo nombre, el cual fue dirigido a docentes de educación básica a partir de un convenio firmado entre la Universidad Nacional Autónoma de México (UNAM) y la Secretaría de Educación Pública (SEP), y cuyo objetivo fue fomentar el desarrollo profesional docente en el uso y aprovechamiento de las TIC en el aula, a fin de que el profesor-participante reconociera distintos modelos pedagógicos y recursos digitales para reorientar su práctica hacia enfoques que coloquen a los estudiantes como eje central de los procesos formativos.

La autoorganización, la autorreferencia, la autogestión y el aprendizaje dialógico fueron los principios que guiaron el modelo educativo del proyecto. Se partió de la noción de que autogestionarse debe invitar a promover aprendizajes significativos, autónomos y colaborativos. Asimismo, se concibió al docente como un sujeto activo, constructor y reconstructor de sí mismo y del conocimiento, pero al mismo tiempo capaz de relacionarse con los otros: "[l]a educación autogestiva [...] visualiza la participación del alumno en una construcción colectiva del conocimiento, y concibe esa colaboración como una de sus tareas" (Ponce, 2016, p.17). El Diplomado comprendió 6 módulos estructurados como cursos autogestivos, con una duración de 20 horas (ver figura 1).

Durante el proceso de diseño de contenidos siempre se tuvo presente que la incorporación de las TIC en un aula no tendría un valor en sí mismo si el y la docente participante no reflexionaba primero sobre su propia práctica y luego sobre cómo una determinada TIC podría contribuir a mejorar una estrategia de enseñanza, pues "[l]a educación en línea sin duda es necesaria, pero insuficiente, si de entrada no se cambian los paradigmas educativos [...] Las TIC, por sí solas, no tienen una función pedagógica y su uso no siempre conlleva procesos pedagógicos innovadores" (Barrón, 2020, p.70). En este sentido, el diseño de cursos autogestivos implicó un doble reto: por un lado, promover que docentes expertos se convirtieran en creadores de contenido (Universidad de la Laguna, 2015) y, por otra parte, desarrollar en las y los docentes participantes actitudes más activas y colaborativas a través de un diseño instruccional reflexivo. 
Revista de la Escuela de Ciencias de la Educación. 2022, Año 18 1(17), 205 - 222.

Enero a junio. Barrón Tirado, M.C.; García Torres, D.B. y Arteaga Barrón, R. La autogestión y la mediación como experiencias para el porvenir educativo.

Figura 1. Estructura del Diplomado en docencia y mediación tecnológica de los aprendizajes

\begin{tabular}{|c|c|c|c|c|c|c|}
\hline Módulo & $\begin{array}{l}\text { 1. Habilidades } \\
\text { digitales }\end{array}$ & $\begin{array}{l}\text { 2. Aprendizaje } \\
\text { centrado en el } \\
\text { estudiante }\end{array}$ & $\begin{array}{l}\text { 3. Currículum } \\
\text { y práctica } \\
\text { docente }\end{array}$ & $\begin{array}{c}\text { 4. De los } \\
\text { programas a } \\
\text { las } \\
\text { secuencias } \\
\text { didácticas }\end{array}$ & $\begin{array}{l}\text { 5. Género, } \\
\text { violencia } \\
\text { y cuidado } \\
\text { de sí }\end{array}$ & $\begin{array}{l}\text { 6. Gestión } \\
\text { escolar y de los } \\
\text { aprendizajes } \\
\text { en entornos } \\
\text { virtuales y } \\
\text { presenciales }\end{array}$ \\
\hline bbjetivo & $\begin{array}{c}\text { Brindar } \\
\text { herramientas y } \\
\text { recursos } \\
\text { tecnológicos } \\
\text { para el } \\
\text { desarrollo de } \\
\text { habilidades } \\
\text { digitales y la } \\
\text { realización de } \\
\text { propuestas } \\
\text { innovadoras en } \\
\text { apoyo al } \\
\text { proceso de } \\
\text { aprendizaje. }\end{array}$ & $\begin{array}{l}\text { Desarrollar } \\
\text { estrategias y } \\
\text { recursos } \\
\text { didácticos que } \\
\text { reconozcan al } \\
\text { estudiante } \\
\text { como eje } \\
\text { central del } \\
\text { proceso } \\
\text { formativo. }\end{array}$ & $\begin{array}{l}\text { Analizar los } \\
\text { elementos } \\
\text { conceptuales y } \\
\text { estructurales } \\
\text { del currículum y } \\
\text { el rol docente } \\
\text { ante ellos. }\end{array}$ & $\begin{array}{l}\text { Revisar los } \\
\text { elementos de } \\
\text { la planeación } \\
\text { didáctica y la } \\
\text { mediación } \\
\text { tecnológica del } \\
\text { aprendizaje. }\end{array}$ & $\begin{array}{l}\text { Analizar la } \\
\text { cultura de } \\
\text { género en } \\
\text { los distintos } \\
\text { ámbitos de } \\
\text { la práctica } \\
\text { docente. }\end{array}$ & $\begin{array}{l}\text { Abordar } \\
\text { elementos } \\
\text { teóricos y } \\
\text { estrategias para } \\
\text { la gestión } \\
\text { escolar. }\end{array}$ \\
\hline
\end{tabular}

Fuente: Elaboración de las autoras, 2021.

El Diplomado inició el 30 de septiembre de 2019 y concluyó el 30 de mayo de 2020. Sin embargo, 2020 fue un año inédito: para marzo, derivado de la declaratoria de la contingencia sanitaria internacional, el gobierno mexicano suspendió las actividades no esenciales, entre ellas la asistencia a los centros escolares, trasladando la escuela presencial a una modalidad virtual. Los conocimientos recién adquiridos por los y las participantes tuvieron oportunidad de ser incorporados y aplicados de manera inmediata, por lo que nos propusimos dar seguimiento a los resultados del Diplomado para conocer su pertinencia y promover conocimiento nuevo con relación a la experiencia y práctica docente, así como en torno al uso de las TIC en los procesos de enseñanza y de aprendizaje de cara a la visualización de un futuro con más incertidumbre que certezas en su porvenir.

Vale la pena tener en cuenta que el imperativo de transformar la función docente ha sido tema de preocupación y ocupación de diversos sectores educativos desde hace varias décadas, o como bien lo menciona Rama (2021, p.17) "La centralidad del docente y la institución ha sido un tema de múltiples intentos fracasados de transformación". Pero, crealmente todos son intentos fracasados? En esta búsqueda de transformación, y de cara a un futuro dominado por la cultura digital, la SEP se ha dado a la tarea de dar soporte y acompañamiento a las y los docentes de educación básica a través de la Coordinación General @prende.mx, instancia creada por decreto en 2014, responsable de planear, coordinar, ejecutar y evaluar periódicamente el 
Revista de la Escuela de Ciencias de la Educación. 2022, Año 18 1(17), 205 - 222. Enero a junio. Barrón Tirado, M.C.; García Torres, D.B. y Arteaga Barrón, R. La autogestión y la mediación como experiencias para el porvenir educativo.

Programa de Inclusión Digital (PID), así como los programas de la SEP relacionados con habilidades digitales y pensamiento computacional (Gobierno de México, 2014 y 2020).

En el marco de las funciones de la Coordinación General @prende.mx, desde 2016 se crea el Programa @prende 2.0 como parte de la Estrategia Digital en Educación para fomentar las TIC en docentes de educación básica de México (Gobierno de México, 2016). Como parte de este programa, el Diplomado se insertó en el componente de desarrollo profesional en TIC a fin de robustecer la práctica de más de cuatro mil docentes. En este sentido, el Diplomado formó parte de una oferta formativa que pretende incorporar las TIC en el aula como mediadores de aprendizaje (UNAM-SEP, 2019). Sin duda, la noción de que la práctica, y por ende la experiencia docente, deben mudar son planteamientos presentes previo a la contingencia sanitaria:

La profesión docente, al igual que ocurre con otros muchos ámbitos laborales y profesionales, se encuentra en un tiempo de mudanza o, si se prefiere, de encrucijada. Sus señas de identidad tradicionales como son la transmisión del saber y del conocimiento a las generaciones más jóvenes, [...] empiezan a tambalearse. Esta nueva profesionalidad es un reto más complejo que el hecho de adquirir el dominio de uso de las TIC o apps aplicadas a la Educación. La nueva profesionalidad docente de la escuela digital, además de competencias tecnológicas, requiere también de asumir un discurso educativo que suponga formar al alumnado como ciudadano culto, crítico y autónomo (Area, 2016, s/p.).

\section{Metodología de investigación}

Para el logro del objetivo de la investigación definimos una metodología mixta. En un primer momento, diseñamos y levantamos una encuesta en línea a las y los 2745 participantes que concluyeron satisfactoriamente el Diplomado. La tasa de respuesta fue de $33.22 \%$; es decir, 912 participantes respondieron completamente la encuesta. El cuestionario se estructuró en 5 secciones configuradas a partir de categorías de análisis definidas para conocer el impacto del Diplomado en las y los participantes, así como en sus prácticas docentes: Sección 1. Perfil sociodemográfico; Sección 2. Infraestructura tecnológica del docente, del estudiante y del aula; Sección 3. Pertinencia de la propuesta didáctica autogestiva y su mediación pedagógica; Sección 4. Incorporación crítica de las TIC a la práctica docente; Sección 5 . Uso y manejo de las TIC. La sección 5 contempló una batería de preguntas recuperadas de Ramírez y Casillas (2016). Las 5 secciones contemplaron preguntas cerradas. De manera particular, las secciones 2 y 3 incluyeron preguntas abiertas que nos permitieron conocer, de manera más detallada, las experiencias docentes durante y posterior al Diplomado, así como la pertinencia del mismo durante el contexto de la contingencia sanitaria. Es importante mencionar que las y los participantes de la encuesta no tuvieron ningún otro incentivo para participar en la misma, salvo el hecho de hacerles saber el valor de sus respuestas como insumo para indagar en torno a la docencia y al uso de las TIC; no se les otorgó ningún tipo de constancia o diploma por su participación ni acudimos a directivos para hacer de su 
participación algo obligatorio. Las y los 912 participantes respondieron el cuestionario en condiciones de absoluta libertad.

La encuesta contó con la participación de un $68.09 \%$ de mujeres y de un $31.91 \%$ de hombres. Del total de mujeres participantes, $66.18 \%$ se dedica a la docencia y del total de hombres participantes, $68.38 \%$ se desempeña como docente. El resto de las y los participantes tienen funciones directivas, son ATP, jefes/as de enseñanza o cuentan con cargos administrativos, de supervisión, entre otros.

En un segundo momento de la investigación, recuperamos, a través de relatos de historias de vida, las experiencias de las y los docentes durante y después del Diplomado. Los relatos de vida se emplean, en este trabajo, desde una perspectiva etnosociológica (Bertaux, 2005) con el propósito de identificar generalizaciones en la particularidad, así como reconstruir las experiencias compartidas simbólicamente por las y los docentes.

Al tratarse de una fase de investigación cualitativa, invitamos a un número reducido de docentes a compartir sus relatos de historias de vida. Para ello, tomamos como criterios el tipo de escuela en la que se desempeñaron durante el ciclo escolar 2019-2020 (rural, urbana o multigrado) y el nivel educativo (preescolar, primaria, secundaria, media superior y superior). La distribución de las y los participantes del momento cualitativo de la investigación por tipo de escuela, se realizó de manera proporcional al total de docentes que por tipo de escuela respondieron la encuesta. Bajo esta lógica de proporción, invitamos a 51 docentes distribuidos de la siguiente manera: 32 docentes de escuelas urbanas, 15 docentes de escuelas rurales y 4 docentes de escuelas multigrado. Obtuvimos 5 relatos de historias de vida: 3 corresponden a docentes de escuelas urbanas (una de preescolar y dos de primaria), 1 corresponde a docente de escuela secundaria rural y 1 más, a docente de escuela primaria multigrado.

Si bien la información recabada hasta ahora ha sido amplia y robusta, en el presente trabajo nos es de gran interés analizar dos categorías que reconocemos como transversales en nuestra investigación: la autogestión y la mediación. Ambas categorías resultan ser temas ampliamente trabajados, pero que cobran relevancia ante el contexto vivido: la experiencia y la función docente han sido trastocadas a partir de lo acontecido durante la contingencia sanitaria derivada de la COVID-19. Sin duda, 2020 fue un año en el que inició una época de incertidumbre, pues las estrategias y planeaciones definidas previo a la declaratoria de pandemia nos daban una determinada seguridad sobre qué y cómo enseñar; sin embargo, el cambio abrupto de modalidad presencial a virtual generó una sensación de pérdida, confusión, desorientación. Ante este panorama y pensando en la educación que requerirá la post-pandemia, recuperamos la autogestión y la mediación como elementos orientadores que contribuyen a trazar nuevas rutas de práctica y experiencia docente en las que la libertad, la creatividad, la reflexión crítica y la construcción participativa del conocimiento sean cualidades inherentes a los procesos de enseñanza y aprendizaje.

\section{Sobre los procesos de autogestión de las y los docentes}

Hablar de autogestión desde el ámbito pedagógico remite a la posibilidad de tomar conciencia de sí y del mundo que nos rodea. 
La autogestión académica es, ante todo y esencialmente, una toma de conciencia [...]de lo que es el estudiar y el conocer, no como un ejercicio abstracto y al margen del tiempo y la sociedad que nos rodean, sino como algo que se produce dentro de ellos y como parte de nosotros, en relación y condicionamiento recíprocos (Revueltas, 1968, p.152).

Las pedagogías autogestionarias cuestionan el autoritarismo de la institución escolar, la directividad de los procesos educativos y la falta de participación democrática impulsada por quienes detentan el poder. Como ejemplo podemos citar los trabajos de Freinet, el Poema pedagógico de Makarenko, El manifiesto de la educación de G. Mendel y Ch. Vogt, Maestros problemas de Neill, la Autogestión pedagógica de Lapassade y la corriente de "pedagogía institucional" francesa. La corriente antiautoritaria señala que la autogestión es ante todo una autogestión personal (Freire, 1971; Ardoino, 1977). Desde este posicionamiento se cuestiona en sentido amplio un orden social establecido.

En todas ellas, la tarea fundamental del maestro es la de establecer una relación pedagógica horizontal, en el sentido de no ejercer poder y dominio a través de los contenidos y de la evaluación, sino en formar conciencias a través de estrategias que posibiliten la construcción permanente de conocimientos, de la reflexión crítica y de la participación responsable, ética y comprometida de los estudiantes, con su aprendizaje y con su comunidad. Los procesos autogestivos están orientados al logro de la autonomía del estudiante. "La autonomía es el actuar reflexivo de una razón que se crea en un movimiento sin fin, de una manera a la vez individual y social" (Castoriadis, 1997, p.12).

De acuerdo con el análisis cualitativo, la autogestión implica crear conciencia y poner atención sobre las habilidades desarrolladas por el propio estudiante y sobre cómo darles orden y coherencia para obtener los resultados planteados: es decir, la autogestión implica el desarrollo de una metodología o de un proceso de aprendizaje. En ese sentido, la autogestión no solo es la capacidad de decidir libremente la manera en la que el estudiante organiza sus recursos para el aprendizaje, y la flexibilidad para adecuarlos a las necesidades del propio proceso de aprendizaje.

Al iniciar el diplomado, ya implementaba las TIC, pero no tenía una metodología y una forma de organizar la manera de usarlas, nunca imagine que esta forma de dar clases, sería la básica con la pandemia, agradezco enormemente a ustedes que nos dieron el seguimiento a nuestra preparación en relación a las TIC (Docente participante entrevistado, abril 2021).

Con el diplomado aprendí que uno es responsable de lo que aprende, cuándo y cómo lo aprende y los medios que utilizas para llegar a ese conocimiento, siempre y cuando lo intentes (Docente participante entrevistado, abril 2021).

Durante el Diplomado, la autogestión también se vio desplegada en la capacidad metacognitiva de las y los docentes participantes. De acuerdo con Flavell (1993 citado en Ponce, 2016), la metacognición es entendida como el 
conocimiento que una persona tiene de las características y limitaciones de su propia capacidad para conocer, así como del control y la regulación que puede ejercer sobre ella. Con base en algunos testimonios de las y los docentes, es posible decir que el diseño didáctico del Diplomado posibilitó que las y los participantes tomaran conciencia sobre sus potencialidades y sus limitaciones para aprender y aprehender los conocimientos adquiridos durante el mismo, al tiempo que les permitió reconocerse como sujetos capaces de asumir la regulación de sus propios procesos de aprendizaje, tal y como se muestra en los siguientes testimonios:

Considero que el curso me obligó a reconocer mis áreas de oportunidad para poder atender a mis pequeños a distancia, darme cuenta que debía lograr llegar a todos, incluso a aquellos que no tienen internet y el diplomado me permitió abordarlos con más confianza (Docente participante entrevistado, abril 2021).

Este curso me ayudó mucho a conocer más acerca de mis habilidades y capacidades al momento de realizar cada actividad de casa sesión, asimismo resolviendo los cuestionarios y exámenes de cada tema. Me ha favorecido en lo personal y laboral porque me dio la oportunidad de conocerme a mí misma y de conocer la capacidad que tengo para resolver las actividades de acuerdo a los tiempos establecidos, así como llegar a la meta para concluir el diplomado (Docente participante, relato de historias de vida, abril 2021).

De manera personal, descubrí que nunca hay que subestimar nuestras capacidades porque uno nunca sabe de lo que es capaz hasta que lo intenta. Por ello, como estrategia para sacar adelante el diplomado me apoyé de los fines de semana con la intención de realizar con detenimiento cada una de las actividades y así lograr los objetivos planteados. Por lo tanto, agradezco ser parte de esta bonita experiencia que además de ser relevante en mi práctica docente me enseñó a ser mejor persona, al cambiar mi mentalidad y propiciar la superación (Docente participante, relato de historias de vida, abril 2021).

Por otro lado, si bien la autogestión promueve el desarrollo de estudiantes activos -es decir, de "sujetos responsables de activar su aprendizaje"-, también es cierto que aprender de manera autogestiva requiere de una motivación que no proviene únicamente del alumno (motivación intrínseca); también se hace necesario considerar la dimensión didáctica de la selección y organización de los contenidos, de las estrategias de aprendizaje, de los recursos de apoyo y de la autoevaluación continua, los cuales constituyen una motivación extrínseca. Ambas motivaciones se articulan y contribuyen a la autogestión como proceso.

En la propuesta autogestiva impulsada en el Diplomado, resalta la importancia de la figura del monitor como una figura de mediación que promueve la motivación extrínseca en el estudiante, activando o reactivando su deseo de estudiar. La educación a distancia, mediada por la tecnología, coloca al estudiante de cara a la información y al conocimiento, invitándolo a ser creativo en su interpretación y aplicación. En este escenario, la figura del docente autocrático que impone su saber y su interpretación de la realidad queda relegada. Cobra relevancia la figura de una guía o de un facilitador que acompañe, que genere 
Revista de la Escuela de Ciencias de la Educación. 2022, Año 18 1(17), 205 - 222.

Enero a junio. Barrón Tirado, M.C.; García Torres, D.B. y Arteaga Barrón, R. La autogestión y la mediación como experiencias para el porvenir educativo.

empatía con las y los estudiantes y que los motive a desarrollar estrategias de aprendizaje significativo y situado.

Considero que fue pertinente la manera cómo se diseñaron los cursos, además, el hecho de contar con una monitora en este proceso, me motivó a continuar con el diplomado (Docente participante entrevistado, abril 2021).

Es importante, a pesar de ser una modalidad en línea, sentirse acompañado por un monitor, y que se puedan aclarar dudas que pudieran surgir (Docente participante entrevistado, abril 2021).

También fue posible identificar que la propuesta autogestiva del Diplomado tuvo un doble alcance: las y los docentes participantes adquirieron herramientas no solo tecnológicas, sino didácticas. Las y los docentes participantes aprendieron a auto regularse, organizar contenidos y diseñar estrategias más activas. Además, la propuesta pedagógica del Diplomado permitió una retroalimentación del sentido autogestivo de los procesos de aprendizaje: tal como se ilustra en los siguientes testimonios, la motivación inicial de las y los participantes por participar en este tipo de diplomados se vio reforzada conforme avanzaban de manera autogestiva en el diplomado, lo que impulsaba su auto-reconocimiento como sujetos activadores de su aprendizaje, su interés en innovar en prácticas más creativas y en transmitir el sentido autogestivo a sus estudiantes.

Es grato decir que cada actividad que se presentó no la miré como una tarea, sino como un reto por superar, porque me incitó a investigar de manera autónoma y repensar mi práctica escolar (Docente participante, relato de historias de vida, abril 2021).

Gracias al Diplomado, ahora tomo en cuenta los intereses de mis alumnos, así como sus habilidades para desarrollar su autonomía en el aprendizaje (Docente participante, relato de historias de vida, abril 2021).

Como participante pude desarrollar mejores habilidades, actitudes y conocimientos. Además de poder generar mejores ambientes de aprendizajes, mayor creatividad e interacción con mis estudiantes, el uso y desarrollo de TIC en el aula, propiciar la autonomía (Docente participante, relato de historias de vida, abril 2021).

La propuesta autogestiva del Diplomado permitió que las y los docentes participantes tomarán conciencia no solo sobre sus propios recursos y métodos para propiciar el aprendizaje, sino que incorporaron el sentido autogestivo en su reconocimiento como sujetos conscientes de lo que saben, de lo que no saben y de lo que quieren y necesitan aprender para generar prácticas centradas en estudiantes autónomos capaces de participar en la construcción de nuevos conocimientos. 


\section{Sobre la mediación pedagógica como experiencia}

La mediación no es un tema reciente y ha sido abordado desde distintas perspectivas. Particularmente para el presente trabajo nos interesa recuperar la noción de Pedagogía de la Mediación (Tébar, 2017; León, 2014), la mediación como un proceso a través del cual es posible la modificabilidad cognitiva y afectiva de un sujeto (Ferreiro y Vizoso, 2008) y la mediación concerniente al papel que juegan las TIC y los recursos educativos digitales (RED) en el proceso educativo, entendidos estos como "artefactos culturales" (Rickenmann, 2006).

Por un lado, Tébar (2017) nos plantea a la educación como una experiencia que debe ser fundante y enriquecedora, humanizante y cargada de valores. Una educación universal debe ser el primer deber de nuestras sociedades; velar por la formación y profesionalización docente debe ser una medida prioritaria para toda autoridad educativa. Para Tébar, la sociedad necesita una educación mediada que permita

desaparecer los prejuicios, los odios, la marginación y la violencia en el mundo. Este es el reto supremo de la modernidad y del futuro incierto que nos espera. Aprender es vivir, pero no basta almacenar conocimientos, es necesario ayudar a que cada ser humano se construya desde dentro para llegar a ser libres, autónomos y vivir plenamente nuestra existencia (Tébar, 2017, p.81).

Lo anterior coincide con León (2014), para quien la mediación pedagógica debe "romper con el paradigma de que educación es la transmisión de conocimientos del profesorado hacia los educandos, es necesario creer y practicar una educación donde el diálogo, la acción mental, el debate y las experiencias significativas sean prácticas cotidianas" (León, 2014, p.142). Dichos planteamientos se pueden ver reflejados en los relatos de docentes-participantes del diplomado:

Hablar de mediación tecnológica de los aprendizajes implica mirarse como agentes de cambio en el ámbito educativo, gracias a que marca una pausa para detenernos a pensar sobre aquello que estamos haciendo bien y aquello que debemos mejorar, porque nuestra labor como docentes es brindar las herramientas para que nuestros alumnos aprendan y movilicen sus competencias al interactuar con los retos que les presenta la sociedad (Docente participante, relato de historias de vida, abril 2021).

Nunca es tarde para seguir aprendiendo y estar actualizándose uno constantemente ante las nuevas generaciones y la tecnología que día a día avanza y que no por ello va a sustituir la presencia del profesor en el aula (Docente participante, relato de historias de vida, abril 2021).

Otro paradigma que se rompe es el relacionado con el tiempo, pues este ha sido regulado por calendarios escolares y por otro tipo de relaciones como "las costumbres sociales, [...] los intereses gremiales docentes y de las concepciones higiénico-pedagógicas, clima, geografía, liturgia, política, economía, higiene y corporativismo son los eslabones semánticos de un discurso teórico y de un orden administrativo y de poder" (Escolano, 1992, p.77), en detrimento de la 
construcción de situaciones educativas, críticas y situadas. Al respecto, los profesores participantes reconocen el valor de regular el tiempo y avanzar a su propio ritmo, iniciar y cerrar un curso de acuerdo a sus necesidades. El valor del tiempo se incrementa en tanto reconocen que su labor como docentes no se limita a dar clases bajo un calendario escolar y a continuar formándose, sino que tienen una carga administrativa que cumplir obligadamente. Al respecto, a través del Diplomado se promovió el respeto por los ritmos de aprendizaje de cada individuo:

Es el primer diplomado autogestivo que he hecho y en lo personal he quedado cien por ciento satisfecha, ya que pude organizar mis tiempos para cursarlo, y eso para mis múltiples ocupaciones fue una gran ventaja (Docente participante entrevistado, abril 2021).

Me fue muy atractivo trabajarlo de esta manera, ya que yo al distribuir mis tiempos puedo trabajar sin presión. Sugerencia: Poder adelantar en los trabajos permitiendo el acceso a los módulos siguientes cuando ya se ha terminado alguno (Docente participante entrevistado, abril 2021).

Amo que los cursos autogestivos respetan tu libertad, tiempos y ritmos de aprendizaje (Docente participante entrevistado, abril 2021).

Por su parte, Ferreiro y Vizoso (2008) recuperan algunos de los planteamientos de Vygotski sobre la zona de desarrollo próximo como base para entender la mediación como un proceso en el que es posible la modificabilidad cognitiva y afectiva de un sujeto a partir de la ayuda del "otro" para aprender y desarrollar su conocimiento potencial, ya sea en espacios presenciales o a distancia. Esa ayuda del "otro" debe cumplir con determinados requisitos para que el aprendizaje deje de ser una simple apropiación y se convierta en "algo" que provoca desarrollo: "tener en cuenta la relación entre lo actual y lo potencial, es decir, lo que puede hacer por sí solo el sujeto que aprende y lo que podría llegar a realizar con la ayuda que se le brinda." (Ferreiro y Vizoso, 2008, p.78). Lo anterior fue posible articularlo desde el diseño instruccional de los cursos autogestivos, ya que si bien el diseño instruccional más clásico se fundamenta en un enfoque conductista que define objetivos y establece indicaciones muy precisas para el logro de la modificación de una conducta (Arshavskiy, 2018), el diseño instruccional de los cursos del Diplomado partió de un enfoque más socioconstructivista, al recuperar la propia práctica docente, para plantear indicaciones que, más que pretender modificar una conducta, tuvieron como intención generar una reflexión antes de dar respuesta: no es lo mismo solicitar "A continuación responda las siguientes preguntas", a pedir: "A partir de su propia práctica docente, reflexione y responda las siguientes preguntas".

Asimismo, el Diplomado contó con una figura que no existía en el proyecto original y que resultó ser fundamental: monitores/as académicos/as, quienes se desempeñaron como ese "otro", como un mediador pedagógico que orientó, acompañó, motivó, dio aliento a las y los participantes; apoyó el tránsito de un estado inicial o real a uno esperado, ideal o potencial, al tiempo que representó el contacto humano en un medio virtual. Las y los monitoras/es introdujeron a 
las y los participantes al Diplomado en general y a cada módulo en particular, indicando la metodología de trabajo, las fechas de inicio y cierre, los medios de comunicación y resolvieron dudas técnicas (cómo ingresar a la plataforma, hacer una captura de pantalla, descargar materiales, por mencionar algunos ejemplos).

Asimismo, dieron seguimiento a las y los alumnos irregulares y enviaron correos invitación a las/los participantes que no habían ingresado nunca a la plataforma.

Así, la modificabilidad cognitiva y afectiva generada a partir la mediación tanto del diseño instruccional de los contenidos como de la figura del monitor/a como mediador, es posible observarla en las siguientes respuestas:

Mucho de lo aprendido en el diplomado me permitió poder ajustar mi práctica a las circunstancias actuales. Me sentía con bases para aprender otras cosas que necesité al inicio y profundizar a lo largo de este año (Docente participante entrevistado, abril 2021).

Desarrollé aún más mi comprensión lectora, así como mis habilidades digitales, lo cual me permitió obtener un nivel satisfactorio en mis evaluaciones (Docente participante entrevistado, abril 2021).

Mi monitor, la maestra en lo personal que me tocó fue muy atenta y pendiente de nuestro seguimiento en el taller (Docente participante entrevistado, abril 2021).

El monitor me apoyó mucho y me motivaba a seguir y no rendirme (Docente participante entrevistado, abril 2021).

Las respuestas recuperadas también nos muestran la importancia del vínculo pedagógico entre monitor/a-participantes, pues independientemente de la modalidad de que se trate, la educación da lugar a la interacción, a la relación y el encuentro con el otro:

Es esto lo que la hace ser, lo que le da posibilidad de ser... asumiendo la responsabilidad, el deseo educativo de ese encuentro, eso es la aspiración, la apertura a que este sea formativo, una experiencia nueva de ser y de saber (Skliar y Larrosa, 2009, s/p).

Al respecto se identifican los siguientes comentarios:

Me sirvieron y han servido bastante los conocimientos y prácticas adquiridos en este diplomado. Y agradezco con mucho cariño y respeto a la maestra monitor, por su tiempo y dedicación hacia nosotros (Docente participante entrevistado, abril 2021).

Quisiera tener una segunda parte de este diplomado, pero con mi misma facilitadora (Docente participante entrevistado, abril 2021). 
Revista de la Escuela de Ciencias de la Educación. 2022, Año 18 1(17), 205 - 222. Enero a junio. Barrón Tirado, M.C.; García Torres, D.B. y Arteaga Barrón, R. La autogestión y la mediación como experiencias para el porvenir educativo.

Felicitar a la monitora por su excelente atención a dudas, ya que respondió en tiempo y forma aclarando cualquier duda que se presentaba (Docente participante entrevistado, abril 2021).

Esos "otros" que median también es posible identificarlos entre los pares participantes, ya que la mediación pedagógica también parte de que el acto pedagógico no debe ser directivo, sino "una forma de interacción entre personas con niveles de experiencia diferentes, donde se parte de la necesidad de compartir para construir en equipo, en un determinado contexto. (León, 2014, p. 141). En este sentido, en el Diplomado participaron docentes, directoras/es, supervisoras/es, asesoras/es técnicos pedagógicos (ATP), entre otras figuras escolares, quienes reconocen los procesos de mediación a través de la interacción con sus pares, como puede identificarse en los siguientes comentarios:

Afortunadamente he podido poner en práctica lo visto en el diplomado, pues esta nueva modalidad de llevar a cabo las clases nos ha servido de impulso para cambiar las formas de manejar los contenidos, además he podido compartir con mis compañeros y así generar más redes de aprendizaje entre colegas (Director participante entrevistado, abril 2021).

Han sido de gran utilidad los conocimientos adquiridos, pues no solo se quedan conmigo, sino que, como director de una escuela primaria, los he compartido con mis compañeros docentes. Gracias por generar este tipo de alternativas de crecimiento profesional (Director participante entrevistado, abril 2021).

Aunque no estoy frente a grupo, invito a los maestros a involucrarse en llevar la educación a distancia separándose de las continuas rutinas de: te envío trabajos, me los regresas y te califico y utilicen classroom por ejemplo para llevar a cabo las estrategias didácticas de una forma divertida, funcional y significativa, desgraciadamente no lo he logrado. Además, como directora, apoyo a los padres de familia que lo requieran a explicarles algún contenido a través de zoom o videollamadas vía whatsapp (Director participante entrevistado, abril 2021).

Como se ha mencionado, varios docentes reconocen el valor del tiempo, pues este tipo de cursos requiere de mejorar la organización propia en cuanto a tiempos y asumir la responsabilidad de su propio aprendizaje, por lo que reconocen la importancia que tuvo el hecho de que el/la monitor/a les hiciera llegar recordatorios. Lo anterior coincide con la idea de que "El mediador debe inducir al empleo, por parte del que aprende, de estrategias que se adecuen a su nivel, estilo y ritmo de aprender, entre otras cosas" (Ferreiro y Vizoso, 2008, p. 79). Los docentes participantes aluden al manejo del tiempo en dos sentidos, mismos que articulan la mediación con la autogestión, el primero orientado a la autoorganización y el otro ligado a la estructuración del curso de manera autogestiva:

Una parte fundamental de este proceso que me permitió seguir adelante, es el apoyo que tuve de la maestra asesora, ya que estaba al pendiente y vigilaba nuestro tiempo para que no se nos fuera a pasar la fecha y estaba al pendiente 
Revista de la Escuela de Ciencias de la Educación. 2022, Año 18 1(17), 205 - 222. Enero a junio. Barrón Tirado, M.C.; García Torres, D.B. y Arteaga Barrón, R. La autogestión y la mediación como experiencias para el porvenir educativo.

de los foros y de lo que hacía falta y también que respondía mis dudas (Docente participante, relato de historias de vida, abril 2021).

Me ha gustado la dinámica del curso autogestivo, la monitora nos avisaba cuándo eran las fechas de entrega de las actividades y eso ayudaba a organizar tiempos, sin presiones (Docente participante entrevistado, abril 2021).

Con la ayuda del monitor logré tener más organización en la realización de mis actividades (Docente participante entrevistado, abril 2021).

Finalmente, Rickenmann (2006), basado en Vygotski, nos plantea el rol central que juegan los artefactos culturales en los procesos de enseñanza y de aprendizaje, y el subsecuente desarrollo de los individuos; parte de la noción de un artefacto cultural como "instrumento cognitivo": "Los artefactos culturales lenguajes naturales y formales, gráficos, textos y obras de arte, etc...[se podría agregar a las TIC]-- son instrumentos que mediatizan las relaciones entre profesor y alumno(s) o entre alumnos y saber" (Rickenmann, 2006, p.2). Para Vygotski (recuperado por Rickenmann, 2006) el desarrollo humano se da de forma triádica, pues nos desenvolvemos a través de un medio social, cultural y semiótico y el contacto con lo social, lo cultural y lo semiótico se da, de manera directa o indirecta, a partir de la mediación del "otro". Lo anterior coincide con el planteamiento de que el proceso de mediación también se da gracias a que un recurso educativo construido media "con la finalidad de mover al alumno en su zona de desarrollo próximo. No hay duda, la tecnología no media por sí misma. El que media es el profesor que emplea la tecnología con una intención" (Ferreiro y Vizoso, 2008, p.79).

Al explorar la plataforma, me motivó para seguir continuando con el diplomado, de igual manera los tiempos son accesibles y los materiales son comprensibles para captar con mayor facilidad y comprender los temas a desarrollar (Docente participante, relato de historias de vida, abril 2021).

Además, reconozco que el mayor obstáculo que tuve que superar fue perder el miedo a explorar las diferentes TIC porque muchas veces desconocía su función y me sentía ignorante al descubrir nueva información. Por ello, es grato decir que cada actividad que se presentó no la miré como una tarea sino como un reto por superar, porque me incitó a investigar de manera autónoma y repensar mi práctica escolar (Docente participante, relato de historias de vida, abril 2021).

\section{CONCLUSIÓN}

En la investigación realizada nos propusimos establecer contacto con los profesores quienes cursaron y concluyeron el Diplomado Docencia y mediación tecnológica de los aprendizajes con la finalidad de recuperar la riqueza de la experiencia y las aportaciones realizadas a su práctica docente, en torno al uso de las TIC en los procesos de enseñanza y de aprendizaje de cara a la visualización de un futuro con más incertidumbre que certezas. 
Con base en la metodología de investigación seguida, indagamos acerca de los procesos de autogestión y mediación como elementos orientadores que contribuyen a trazar nuevas rutas de práctica y experiencia docente. A través de los relatos de vida se buscó dar voz a los docentes; en la medida en la que se visibilice la voz de estos actores y en la que se reconozca su identidad y su individualidad se les podrá dotar de su carácter político y social a partir de los cuales puedan ser parte de su tiempo histórico y transformarlo. En este sentido, nuestras cinco historias de vida se nutren y retroalimentan de las más de novecientas respuestas de 5 preguntas abiertas, las cuales también reflejan algunos atisbos de historias de vida a través de los cuales se refuerza la necesidad de recuperar la voz de los docentes como insumos de análisis valioso.

En cuanto a la autogestión promovida a través del Diplomado se puede reconocer un doble alcance: las y los docentes participantes adquirieron tanto herramientas tecnológicas como didácticas. Asimismo, aprendieron a autorregularse, organizar contenidos y diseñar estrategias más activas. Cabe señalar que la propuesta pedagógica del Diplomado permitió una retroalimentación del sentido autogestivo de los procesos de aprendizaje.

Por otra parte, es posible identificar que la mediación en el Diplomado se generó a partir de dos vías. La primera conjunta dos artefactos culturales: una plataforma educativa digital a la cual se accede a través de diversos dispositivos tecnológicos (computadora, teléfono celular, Tablet), la cual contiene una serie de recursos educativos digitales (RED) creados en distintas herramientas digitales (documentos pdf, infografías, videos, blogs, repositorios y bibliotecas digitales, entre otros) cuya creación, selección y organización tuvo la intencionalidad de cumplir con una serie de objetivos y competencias. La segunda vía se refiere al proceso de mediación operado por las y los monitores/as. En este sentido, se reconoce a la figura del monitor/a como una figura que articula tanto los procesos de mediación como los procesos de autogestión pedagógica.

Sin duda, el Diplomado resultó oportuno dadas las circunstancias derivadas de la pandemia, y ello se refleja en la información presentada con antelación. La mediación y autogestión son experiencias que contribuyen a un cambio. Son estrategias que contribuyen a transitar a procesos educativos más centrados en el desarrollo de un estudiante autónomo; a trascender la figura del docente como explicador, al docente como creador de una nueva mediación y de procesos autogestivos.

\section{REFERENCIAS}

Ardoino, J. (1977). Educación y política. Propósitos actuales de la educación II. Gauthier-Villars.

Area, M. (2016). Ser docente en la escuela digital. Suplemento Profesional de Magisterio, (22). Recuperado el 27 de julio de 2021 de https://goo.gl/SGGsoO 
Arshavskiy, M. (2018). Diseño instruccional para el aprendizaje en línea: guía esencial para la creación de cursos exitosos de educación en línea. Createspace independent publishing platform.

Barrón, C. (2020). La educación en línea. Transiciones y disrupciones. IISUE, Educación y pandemia. Una visión académica (66-74). UNAM. Recuperado el 27 de julio de 2021 de http://www.iisue.unam.mx/nosotros/covid/educacion-y-pandemia

Bertaux, D. (2005). El análisis de un relato de vida. En D. Bertaux, Los relatos de vida. Perspectiva etnosociológica. 73-102. Edicions Bellatera.

Bolívar, A. (2014). Las historias de vida del profesorado. Voces y contextos. Revista Mexicana de Investigación Educativa, 19 (62), 711-734.

Castoriadis, C. (1997). Poder, política, autonomía "Un mundo fragmentado". Altamira.

Contreras, J. y Pérez de Lara, N. (2013) (comps.). Investigar la experiencia educativa. Morata.

CUAED (2020). Diplomado en docencia y mediación tecnológica de los aprendizajes. UNAM. Recuperado el 30 de mayo de 2020 de https://trayectorias.cuaed.unam.mx/sep/.

Escolano, A. (1992). Tiempo y Educación. Notas para una genealogía del Almanaque escolar. Revista de Educación, (298), 55-79.

Ferreiro, R. y Vizoso, E. (2008). Una Condición Necesaria en el Empleo de las TICs en el Salón de Clases: La Mediación Pedagógica. Posgrado y Sociedad, 8(2), 72-88.

Freire, P. (1971). Pedagogía del oprimido. Siglo XXI.

Gobierno de México (31 de octubre de 2014). Decreto de Creación de la Coordinación General @prende.mx. Recuperado el 27 de julio de 2021 de https://www.gob.mx/aprendemx/documentos/decreto-de-creacion-de-lacoordinacion-general-prende-mx.

Gobierno de México (7 de noviembre de 2016). Presentación del nuevo Programa @prende 2.0. Recuperado el 27 de julio de 2021 de https://www.gob.mx/aprendemx/prensa/presentacion-del-nuevoprograma-prende-2-0-ciudad-de-mexico-a-7-de-noviembre-de-2016

Gobierno de México (29 de octubre de 2020). Coordinación General @prende.mx. "¿Qué hacemos?" Recuperado el 27 de julio de 2021 de https://www.gob.mx/aprendemx/que-hacemos.

León, G. (2014). Aproximaciones a la mediación pedagógica. Revista Calidad en la Educación Superior, 5(1), 136-15. Recuperado el 27 de julio de 2021 de https://dialnet.unirioja.es/servlet/articulo?codigo $=5580842$

Morelli, S. (2021). El porvenir de las políticas curriculares. En Morelli, S. (coord.), Políticas curriculares. Experiencias en contextos latinoamericanos. Homo Sapiens Ediciones.

Ponce, M.E. (2016). La autogestión para el aprendizaje en estudiantes de ambientes mediados por tecnología. Diálogos sobre educación, (12), 1-23. Recuperado el 24 de mayo de 2018 de http://dialogossobreeducacion.cucsh.udg.mx/index.php/DSE/article/view/ 258 
Rama, C. (2021) La nueva educación híbrida. Cuadernos de Universidades 11. UDUAL.

Ramírez, A. y Casillas, M. A. (2016). Encuesta de Saberes Digitales de los Actores Académicos. Versión septiembre 2016. En Casillas, M. y Ramírez, A. (2021), Saberes digitales en la educación. Una investigación sobre el capital tecnológico incorporado de los agentes de la educación. Brujas.

Revueltas, J. (1968). ¿Qué es la autogestión académica? Aportes del pensamiento crítico latinoamericano, Revista OSAL-CLACSO, IX, 24 Octubre de 2008.

Rickenmann, R. (2006). El rol de los artefactos culturales en la estructuración y gestión de secuencias de enseñanza-aprendizaje, Conférence invitée, Actes du 1er simposio internacional de educación y formación docente, Universidad de Antioquia, Medellín, Colombia. Recuperado el 17 de mayo de 2021 de http://www.unige.ch/fapse/clidi/textos/artefactos-culturalesRR.pdf

Skliar, C. y Larrosa, J. (2009). (Comp.) Experiencia y alteridad en educación. FLACSO Argentina-Homo Sapiens.

Tébar, L. (2017). La función mediadora de la educación. Foro Educacional, (28), 79-80.

UNAM-SEP (2019). Convenio de colaboración. Documento interno de trabajo. UNAM-SEP.

Universidad de La Laguna (19 de enero de 2015). El papel del docente en los entornos educativos online [Archivo de video]. Youtube. https://youtu.be/ha7Zc9q2eew.

Vygotski, L. (2001). Pensamiento y Lenguaje; Conferencias sobre psicología, en Obras escogidas. Tomo II. Antonio Machado Libros. 